\title{
様々な圧力測定を利用したスラリー中の粒子分散・凝集状態評価
}

\author{
森 隆昌* \\ 法政大学生命科学部環境応用化学科， $=184-8584$ 東京都小金井市梶野町 3-7-2.
}

\section{Evaluation of Particles Dispersion and Flocculation State in Slurries by Using Various Pressure Measurement}

\author{
Takamasa MORI* \\ Dept. Chemical Science and Technology, Hosei University, 3-7-2 Kajino-cho, Koganei, Tokyo 184-8584, Japan.
}

Received June 6, 2018; Revised July 17, 2018; Accepted July 21, 2018

\begin{abstract}
In this paper, we introduce novel slurry characterization techniques, the hydrostatic pressure measurement and the osmotic pressure measurement. In the hydrostatic pressure measurement, the particles dispersion and flocculation state in the slurry containing the micron or sub-micron particles be determined from the decreasing rate of its hydrostatic pressure (the time change of the hydrostatic pressure). The hydrostatic pressures of single and multi component slurries are introduced and their particles dispersion and flocculation states are discussed.

On the other hand, the osmotic pressure measurement can evaluate the particles dispersion and flocculation state in slurries containing the nano particles. It was demonstrated that the osmotic pressure of the nano particles slurry increased as the particles in the slurry well dispersed, corresponding to the particles concentration of the sampled slurry after ultracentrifugation.
\end{abstract}

\section{KEY WORDS}

slurry, particle dispersion, hydrostatic pressure measurement, osmotic pressure measurement

\section{1 はじめに}

鋳込み成形やシート成形などのセラミックス湿式成形プロ セスでは，プロセスの出発となるスラリー(粒子懸濁液) の 特性を制御することが重要である ${ }^{1)}$. 湿式成形によって製造 される製品の特性が，スラリーの特性，特にスラリー中の粒 子分散・凝集状態に強く依存することは既に広く認知されて おり，研究開発段階のみならず，プロセス管理の一貫として も, 様々な方法でスラリー中の粒子分散・凝集状態の評価・ 制御が行われてきている2).

各プロセスによって望まれるスラリー中の粒子分散・凝集 状態は異なるため, スラリー最適化のためには, まず現状の スラリーにおいて，粒子分散・凝集状態がどうなっているの かを的確に評価することが必要不可欠である。このスラリー 中の粒子分散・凝集状態の評価は，長年にわたり様々な方法 で取り組まれてきたことではあるが,「的確に」評価できてい るのかどうかが問題であると我々は考えている ${ }^{3-6)}$. それは,

* Corresponding author, E-mail: tmori@hosei.ac.jp
今なお多くの産業現場で，スラリー評価結果のみからでは製 品特性を完全に予測・制御できないという話を聞くからである. そこで，本稿では，スラリー評価の現状を概観するととも に, 上記の様なスラリー評価に関する産業界の要望に応えら れるようにと開発してきた新しいスラリー評価法である沈降 静水圧測定法及び浸透圧測定法について紹介する.

\section{2 スラリー評侕の現状}

スラリー中の粒子分散・凝集状態を評価する方法としては 様々なものが提案され，また商品化されている，現状のセラ ミックス成形では主にサブミクロン程度以上の粒子からなる スラリーが使われていることが多いため，このようなスラ リーを対象とした粒子分散・凝集状態の評価法をあげると， 重力・遠心沈降挙動の観察を利用した評価法 (沈降法 $)^{7)}$, レーザー回折・散乱法による粒子径分布測定を利用した評価 法 $^{8)}$ ，回転粘度計による見かけ粘度の測定を利用した評価法 ${ }^{9}$, 超音波減衰法 ${ }^{10)}$, あるいは節い分けによる評価法などがあ る. 中でも比較的よく使われている沈降法, レーザー回折・ 
散乱法による粒子径分布測定を利用する方法，回転粘度計に よる見かけ粘度の測定を利用する方法ついてごく簡単に現状 を述べる。

沈降法は，スラリー中の粒子が溶媒との密度差で沈降する ことを利用した評価方法であり，原理的には古くから知られ ている方法である．近年では光の透過を利用して沈降途中の スラリー中の粒子濃度分布まで計測できる評価装置も市販さ れている．沈降法はセラミックス成形プロセス用のスラリー 評価でも使用されており，噴霧乾燥顆粒の形状や密度との関 係を報告した例 ${ }^{11)}$ ，鋳込久成形体の密度と沈降後の堆積物の 充填率の関係を報告した例 ${ }^{12)}$ がある。一方で，近年の多様化 したスラリーの中には, 電池材料スラリー（黒色）のように, 沈降挙動の観察が極めて困難なスラリーもある。

次にレーザー回折・散乱法による粒子径分布測定について 述べる。この方法は，スラリーにレーザー光を照射したとき に，レーザー光が粒子に当たり散乱することを利用し，散乱 パターンから粒子径（粒子径分布）を求める方法である。 ラリー中の粒子が凝集している場合の方が，分散している場 合よりも粒子径が大きくなることから，粒子の分散・凝集状 態を定量評価できるとするものである。粒子径分布測定装置 は多くのセラミックス関連企業で使用されているため, これ を利用したスラリー評価も広く実施されているようである が，前述の通り，製品特性を予測できないという話は多い． その原因であるが，我々は「粒子濃度」にあると考えてい る. Fig. 1 は Woodcock の式 ${ }^{(3)} に よ り$ 計算したスラリーの濃 度（体積濃度）と粒子間距離の関係を表している。計算はセ ラミックス成形でよく用いられると言うことで, サブミク ロン $(0.5 \mu \mathrm{m})$ 粒子を想定した。 セラミックス成形で用いら れるスラリーは一般的に高粒子濃度であり，体積濃度で 40 〜 50\%にもなるスラリーもある。このような高粒子濃度の スラリーは直接レーザー回折・散乱法で測定することはでき ず，ほとんどの場合，希釈してから粒子径分布を測定し，ス ラリー評価している，場合によっては何万倍，あるいはそれ 以上希釈することも珍しくない。この時，粒子間距離は 2 3 桁も広がることになる。したがって，粒子間距離が全く異 なる状況で評価した結果で製品特性が完全に予測できないの

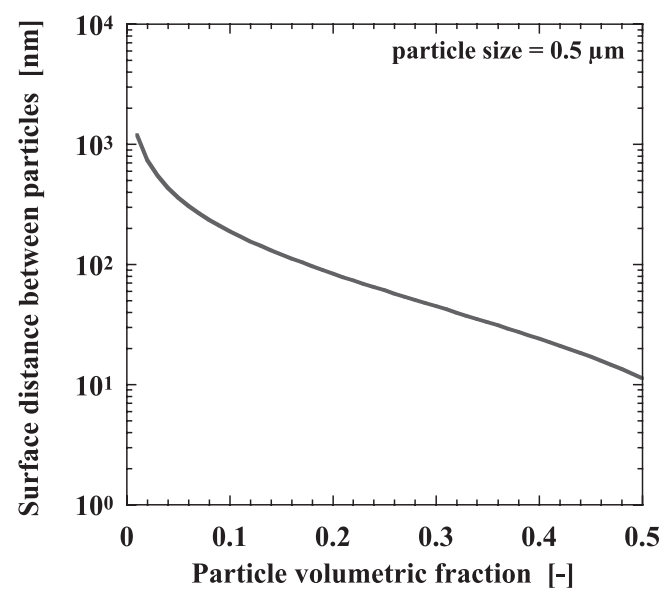

Fig. 1 Relationship between particle concentration and surface distance.
はある意味では当然と考えられるかもしれない，希釈操作に よって，凝集体がほぐれてしまう可能性があること，また， 粒子間距離が标違いに広がり粒子衝突頻度が少なくなるため に，ほぐれた凝集体が再び形成されにくい状況になることに 留意することが重要であると考えられる。

回転粘度計による見かけ粘度測定も広く行われている. 「見かけ粘度が低い=スラリー中の粒子が良く分散している =緻密な成形体ができる」とされ，見かけ粘度の值でスラ リーを最適化，管理しようとされてきた．確かにこのような 考え方はかなりのスラリーであてはまることが知られている が，その一方で，見かけ粘度が最も低いスラリーから最も密 度の高い成形体が得られなかったという，見かけ粘度と充填 性のミスマッチが報告された例も複数存在している ${ }^{14-20)}$. 例 えばFig. $2^{14)}$ に示すアルミナスラリーの例（アルミナ：AES$11 \mathrm{E}$, 住友化学, $0.48 \mu \mathrm{m}$, 分散剂：ポリカルボン酸アンモニ ウム，粒子濃度 $35 \mathrm{vol} \%$ の水系スラリー）では，見かけ粘度 (B 型粘度計で測定，相当剪断速度 $12.4 \mathrm{~s}^{-1}$ ) が最も低くなる 分散剂添加量よりもわずかに多く分散剂を加えて見かけ粘度 が少し高くなったスラリーから, 最も密度の高い成形体（こ の図はスラリーを重力沈降させた時の堆積層の充填率を示し ているが, 堆積層充填率の大小と成形体密度の大小とはよく 一致することがわかっている）が得られることを示してい る. 他にも Greenwood $~^{10}$ は, バインダ添加量を変化させた 水系アルミナスラリーのシート成形に扔いて, 焼結体密度の 大小がスラリーの見かけ粘度の大小と完全には一致しないこ

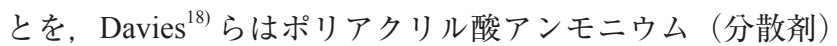
の添加量を変えたアルミナスラリーで見かけ粘度の大小と成 形体密度の大小が完全には一致しないことを報告している.

あるいは，高橋ら ${ }^{20)}$ は見かけ粘度測定結果とスラリーの直 接観察結果を比較し，見かけ粘度には差がないスラリーで あっても，直接観察した粒子分散状態には明確な違いがある 場合があると報告しており，これも見かけ粘度とスラリー中 の粒子分散・凝集状態とのミスマッチの例と言える。

このように見かけ粘度測定は広く実施されており，分散状 態を的確に評価できたという報告例 21,22 もあり，有力なスラ リー評価手法の 1 つではあるが，上記の様なケースもあるこ

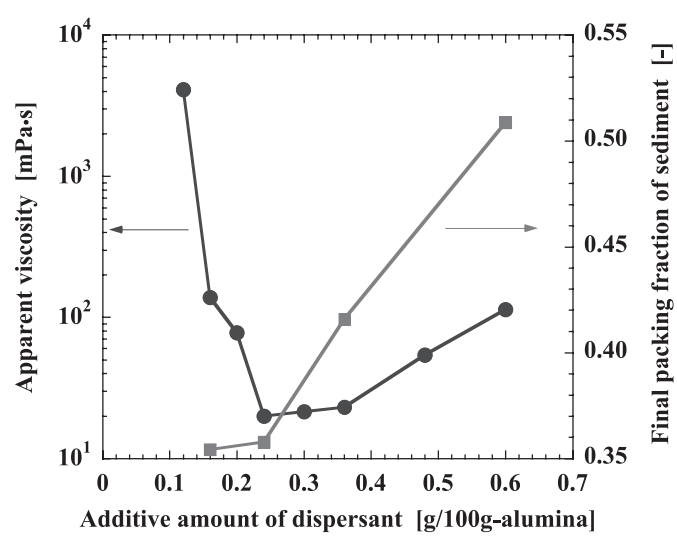

Fig. 2 Apparent viscosity and final packing fraction of sediment for alumina slurries ${ }^{10)}$ 
とは考慮してスラリー条件の最適化に利用することが望まし いと考えられる。

\section{3 沈降静水圧測定法によるスラリー評価}

\section{1 沈降静水圧測定法の原理}

以上のようなこれまでのスラリー評価法に対する考察か ら，セラミックス成形プロセスを制御し，スラリー評価から か製品特性を予測するためには，スラリーの濃縮過程（粒子 濃度がスラリー調製時の濃度から成形体に近い濃度（密度） まで増加していく過程）に扔ける粒子分散・凝集状態（の変 化）を捉えることが重要であるという考えに至った。これは 粒子濃度が増加すると平均粒子間距離が縮まり, 粒子衝突頻 度が増加するため，粒子が㠜集する可能性が高くなることか ら，調製直後には粒子が分散していたスラリーでも粒子濃度 が増加すると凝集する場合があるからである ${ }^{23)}$. 本稿ではセ ラミックス製品の重要な特性の1つである密度を予測・制御 するという観点から，我々が開発した新しいスラリー評価法 の概要を紹介する.

まず，セラミックス製品（焼結体）の密度は，焼結前の成 形体の密度に強く依存している。成形体の密度がある程度高 くなければ，焼結工程をいかに工夫しても，それだけで密度 の高い製品を得ることは困難である。したがって，スラリー 評価によって製品の密度を予測・制御するということは，成 形体の密度を予測・制御することに他ならない。この成形体 の密度制御が重要であるという考え方は広く認知されている ことである。 そこで，以下ではアルミナスラリーを例に，ス ラリー評価結果と成形体密度がどのように関係するのか，そ れを踏まえて，どのようなスラリー評価法で何を評価するの
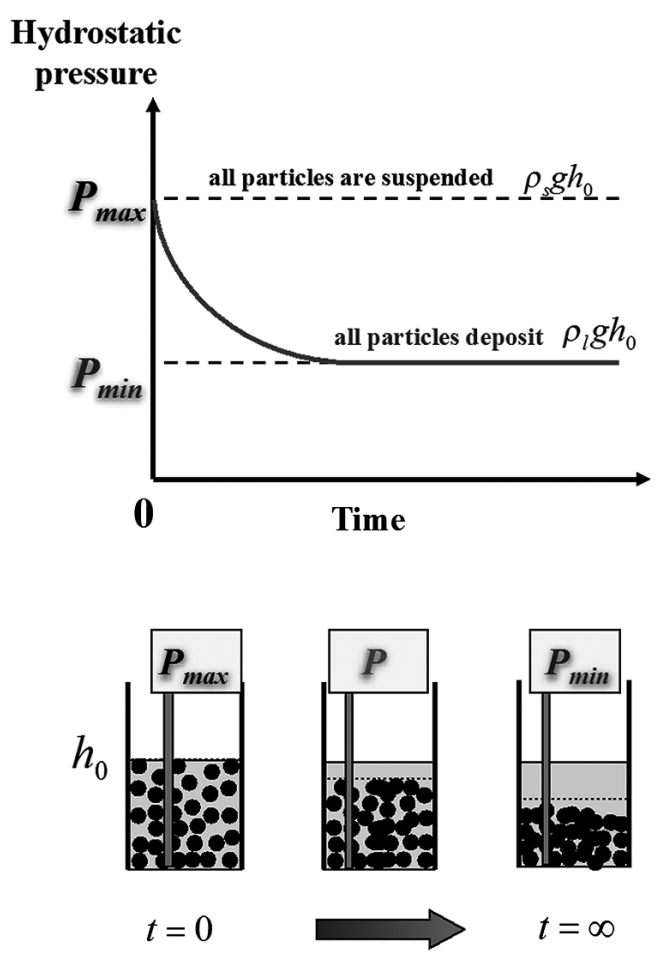

が成形体密度を予測する上で有効であるのかを述べることに する。

今回は，スラリー評価として広く行われている見かけ粘度 の測定と, 前述の「スラリーの濃縮過程における粒子分散 • 凝集状態（の変化）を捉えることが重要」という考えに基つ き我々が提案している沈降静水圧測定法 ${ }^{(623-27)}$ について比較 した結果を示す，見かけ粘度測定についてはすでに多くのテ キストもあるためここでは省略するが，回転粘度計，レオ メーターによって測定される特性值である. Fig. 3 には沈降 静水圧測定法の概要を示す，評価したいスラリーを沈降管に 入れ静置する（重力場で沈降させる）というところは, 従来 の回分沈降試験と同様である。このとき，スラリーの液面か ら深さ $h_{0}$ の位置で静水圧を測定するというところが新規な 点である. Fig. 3 に示したように，スラリー中の全粒子が浮 遊している場合には，媒液が粒子を支えるため，スラリーを 入れた容器底部の静水圧は全粒子の質量と媒液の質量の和に 相当する。このときの圧力が $P_{\text {max }}[\mathrm{Pa}]$ である. $P_{\text {max }}$ は, スラリー の密度 $\rho_{\mathrm{s}}\left[\mathrm{kg} \cdot \mathrm{m}^{-3}\right]$ を使って以下のように求めることができる.

$$
\begin{aligned}
& P_{\max }=\rho_{\mathrm{s}} g h_{0} \\
& \rho_{\mathrm{s}}=\phi \rho_{\mathrm{p}}+(1-\phi) \rho_{1}
\end{aligned}
$$

ここで $h_{0}[\mathrm{~m}]$ は液面から圧力測定部までの深さ， $\phi[-]$ は久 ラリー中の粒子体積分率, $\rho_{\mathrm{p}}, \rho_{1}\left[\mathrm{~kg} \cdot \mathrm{m}^{-3}\right]$ はそれぞれ粒子及び 溶媒の密度である。一方, 粒子がすべて沈降し, 堆積層を形 成した場合, 粒子の質量は沈降管の底で支えられるために, 底部の静水圧は媒液のみの静水圧となる。このときの圧力 が $P_{\text {min }}\left(=\rho_{1} g h_{0}\right)$ である.いずれのスラリーに扔いても静水圧 は沈降に伴って $P_{\text {max }}$ から $P_{\text {min }}$ まで変化するが，粒子が凝集し

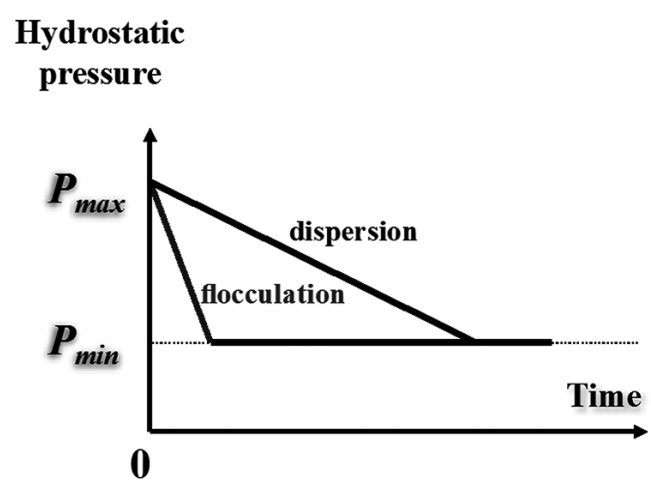

dispersion

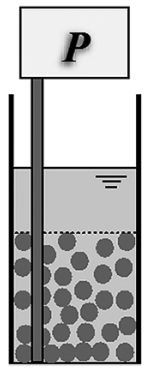

flocculation

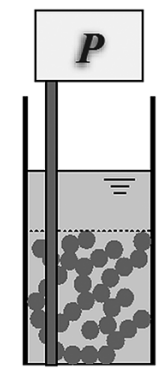

Fig. 3 Schematic illustration of hydrostatic pressure measurement. 


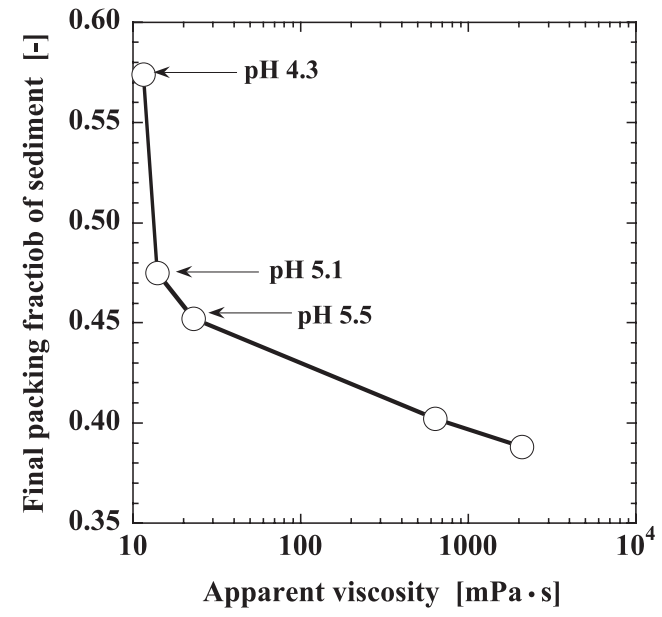

Fig. 4 Relationship between apparent viscosity and final packing fraction of sediment.

ているスラリーでは，粒子が良く分散しているスラリーに比 べ, 底部への粒子の堆積速度が速くなるため, 静水圧の減少 速度が大きくなる。したがって，この静水圧の減少速度の違 いから粒子集合状態を評価することができる．また，この評 価法では沈降に伴ってスラリー層の粒子濃度は増加していく ため前述の「スラリーの濃縮過程に押ける粒子分散・凝集状 態 (の変化)」を捉えることができる. Fig. $4^{24)}$ には従来法で あるスラリーの見かけ粘度測定結果と, 成形体密度（ここで は成形体密度の大きさと相関がある沈降試験後の堆積層の最 終充填率を示してある）の関係を示す。この図は一次粒子径 が $3 \mu \mathrm{m}$ の研磨材を粒子濃度が $30 \mathrm{vol} \%$ となるように水と混 合したスラリーの結果で，スラリーの $\mathrm{pH}$ を変化させること で分散・凝集状態を制御している。四から分かるように, $\mathrm{pH} 4.3 ， 5.1 ， 5.5$ のスラリーを比較すると，これらの見かけ 粘度の差はごくわずか $(2 \mathrm{mPa} \cdot \mathrm{s})$ であるにも関わらず，成 形体密度に相当する堆積層の最終充填率は 0.1 以上異なって いる，すなわち，見かけ粘度の評価の久から成形体密度を精 度良く予測・制御することが難しいことを示している。一方 で, 沈降静水圧測定結果から求めた「スラリーの濃縮過程に 打ける粒子分散・凝集状態 (の変化)」を表す指標と堆積層 の最終充填率との関係を Fig. . $^{24)}$ に示す。 沈降静水圧測定結 果から「スラリーの濃縮過程に打ける粒子分散・凝集状態 (の変化)」を表す指標として, 静水圧が $P_{\text {min }}$ に達するまでの 時間をとっている. 静水圧が $P_{\min }$ に達するまでの時間が長く なるほど，粒子が完全に堆積するまでに時間がかかることを 意味し, 濃縮過程全体を通して粒子が分散して堆積したこと を表している，図から分かるように，静水圧が $P_{\min }$ に達する までの時間が長くなるほど, 成形体密度に相当する堆積層充 填率が高くなっており, 緻密な成形体, 製品が得られること が期待される. 静水圧が $P_{\min }$ に達するまでの時間の違いは,

濃縮過程全体を通した粒子分散状態の違いを表していること から考えると，この関倸は妥当であり，従来の見かけ粘度測 定よりも精度良く成形体，焼結体密度を予測・制御できる可 能性があると期待される。

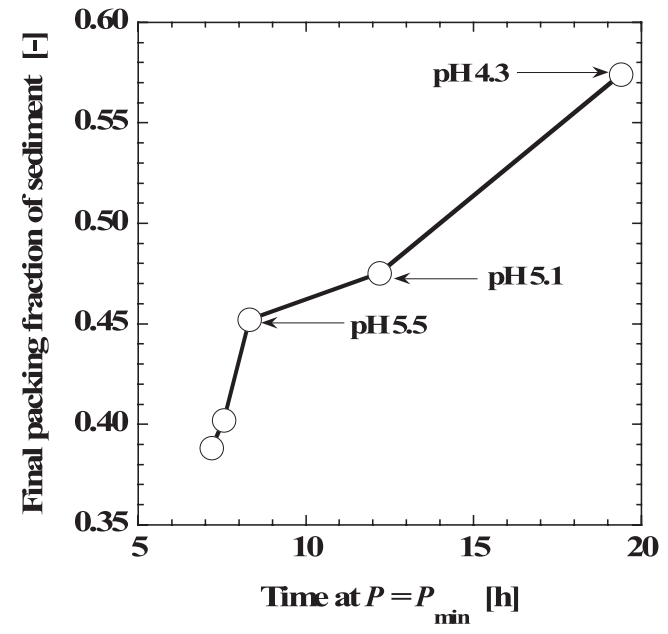

Fig. 5 Relationship between the time at $P=P_{\min }$ and final packing fraction of sediment.

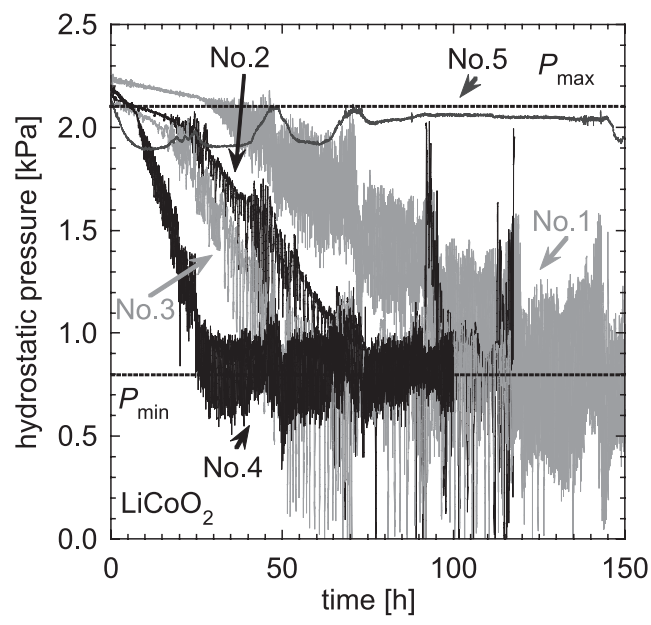

Fig. 6 Hydrostatic pressure curves of $\mathrm{LiCoO}_{2}$ slurries ${ }^{23)}$.

\section{2 沈降静水圧測定法の多成分スラリーへの応用}

前節のような単成分の粒子のスラリーを沈降静水圧測定法 で評価した例以外に, 多成分の粒子のスラリー評価に応用し

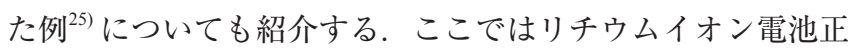
極スラリーについて述べる。リチウムイオン電池正極スラ リーは活物質と導電剂と呼ばれる 2 成分の粒子に分散剂，バ インダーが添加されたスラリーである。ここでは，リチウム イオン電池正極スラリー中の大部分の重量を占める活物質粒 子単独のスラリーと活物質・導電剤の混合スラリー（実際の

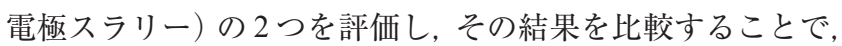
スラリー設計指針の決定に役立てた. Fig. $6^{25)}$ に活物質粒子 単独のスラリーの, Fig. $7^{25}$ に活物質・導電剤の混合スラリー の沈降静水圧測定結果を示す. 使用した活物質, 導電剂はそれ ぞれコバルト酸リチウム (平均粒子径 $10 \mu \mathrm{m}$, 密度 $4.3 \mathrm{~g} \cdot \mathrm{cm}^{-3}$ ), アセチレンブラック (平均粒子径 $50 \mathrm{~nm}$, 密度 $2.0 \mathrm{~g} \cdot \mathrm{cm}^{-3}$ ) である。これらを活物質粒子単独のスラリーでは粒子濃度が $48 \mathrm{vol} \%$ となるように，活物質・導電剂の混合スラリーでは 粒子濃度が $50 \mathrm{vol} \%$ となるように $n$-メチル-2-ピロリドンと混 合した。この時添加する高分子添加剂の種類を変化させて異 


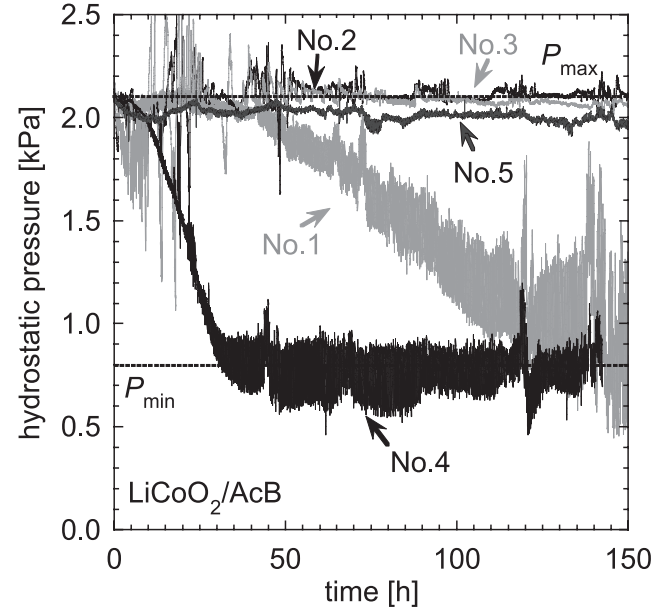

Fig. 7 Hydrostatic pressure curves of $\mathrm{LiCoO}_{2} / \mathrm{AcB}$ slurries ${ }^{23)}$.

なる特性を持つ 5 種類のスラリーを調製した．高分子添加剤 の詳細は非開示のため, No. 1〜No. 5 とのみ表記するが，こ こでは多成分粒子の分散状態が違う場合に，沈降静水圧測定 ではどのような違いがでるのかに注目する。まず活物質単独 のスラリーでは, No. 5 の添加剤の場合が最も沈降静水圧の 減少速度が遅く, 活物質の分散状態が最も良いことが分かる. 興味深いのは活物質・導電剂の混合スラリーになると, 活物 質単独ではそれほど分散がよくなかった（沈降静水圧の減少 速度が大きかった）No.2, 3 の添加剤の場合も, No. 5 の場 合と同様に沈降静水圧の減少速度が遅くなるという点である. これはNo. 2, 3 の添加郕は導電剂をネットワーク状に凝集さ せるためであると考えられる（導電剤単独のスラリーの沈降 試験, 流動曲線の測定から, ネットワーク状に凝集している ことを確認している ${ }^{25)}$ )。すなわち, 導電剤のネットワーク が活物質の沈降を抑制し, 活物質があたかも高粘性流体中を 沈降するように振る舞うため, 沈降速度が極めて遅くなった ということである. 活物質の沈降速度が速いと活物質と導電 剤の沈降速度差から偏析が起こる可能性があるため, 活物質 の沈降抑制は重要な課題であり, その課題に対して, 活物質 の分散をよくすることで沈降速度を遅くするだけでなく，も う一方の成分, 導電剂をネットワーク状に凝集させ沈降を抑 制するという方法もあり得るということを示すことができた. 活物質・導電剂の混合スラリーのみの評価で全てを判断する のではなく, 今回の例であれば活物質単独のスラリー, 導電 剂単独のスラリーの評価とうまく組み合わせることで, 混合 スラリー中の粒子分散状態がある程度推定できたと言える.

\section{4 ナノ粒子スラリーの評価}

沈降静水圧測定法は沈降法の一種であり, 粒子が沈降する ことが評価には必要不可欠である。しかしながら，粒子径が $100 \mathrm{~nm}$ 以下のいわゆるナノ粒子スラリーでは, 粒子の沈降速 度は極めて遅いため, 沈降静水圧測定法で評価するのは困難 になる。このようなナノ粒子スラリーにおいてはスラリーの 別の圧力，すなわち，スラリーの浸透圧に注目することが有 効ではないかと考えている.ナノ粒子スラリーでは測定可能

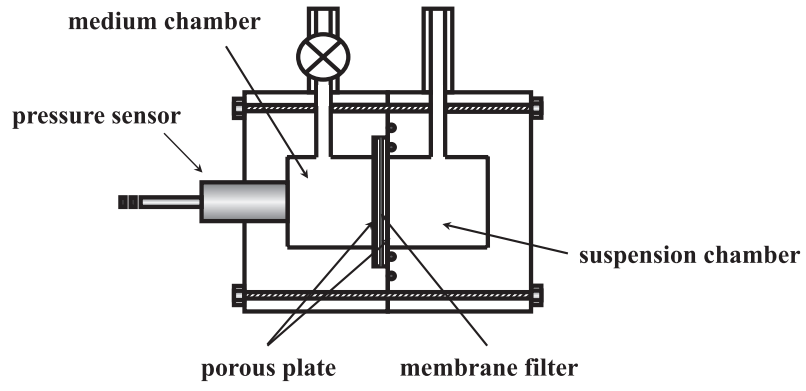

Fig. 8 Schematic illustration of the measurement device of the osmotic pressure $^{32)}$.

な浸透圧が発生し ${ }^{28)}$, Carnahan-Starlingの式から予想されて いるように, 粒子の個数濃度が大きいほどエントロピー効果 で浸透圧は大きくなる ${ }^{29)}$. また，水系スラリーであれば粒子 は帯電し電気二重層が形成されているが, Strauss らのモデル 計算にあるように，粒子の帯電が大きいほど電気二重層の重 なりによってイオン濃度が増加し, 浸透圧が大きくなる ${ }^{30)}$. したがって，粒子が分散しているスラリーほど粒子の見かけ 個数濃度（凝集している場合は凝集体を 1 個と考える）が大 きくなり浸透圧は大きくなると考えられる，また，粒子が強 く帯電しているときは静電反発力により粒子は分散している と考えられるので, この場合も, 粒子が分散しているほど浸 透圧が大きくなるということになる．したがって，ナノ粒子 スラリーの浸透圧から粒子の分散状態を評価できると考えら れるが，ナノ粒子スラリーの浸透圧については実測した例は ほとんどなかった。 そこで，これまでに我々が測定した異な る分散状態のナノ粒子スラリーの浸透圧について紹介する.

ナノ粒子スラリーの浸透圧測定方法の詳細は文献 ${ }^{31,32)}$ を参 照頂きたいが，Fig. $8^{32)}$ に示す装置でナノ粒子スラリーの浸 透圧を測定する. Fig. $9^{32)}$ にはジルコニアナノ粒子スラリー の浸透圧測定結果を示す。ここではスラリーの $\mathrm{pH}$ を変える ことで異なる分散状態に調整している．図の横軸の粒子濃度 は，スラリーを遠心分離し，上部に残った粒子の濃度を測定 したもので，粒子が分散しているほど粒子濃度は大きくな る.この結果から, 上部に残った粒子濃度が大きくなるほど, すなわち, 粒子が分散しているほどスラリーの浸透圧は大き くなっており, 浸透圧測定からナノ粒子スラリーの分散状態 が評価できることが示された。同様の結果が, アルミナ及び シリカのナノ粒子スラリーで得られており, 水系のナノ粒子 スラリーについては浸透圧測定結果が分散状態とょく一致し ている. 今後は更に多様なナノ粒子スラリーの評価を行うこ とで浸透圧測定の適用範囲を検証していく予定である.

\section{5 おわりに}

以上のように, 沈降静水圧測定法は, これまでの見掛け粘 度よりも成形体, 焼結体の密度を的確に予測・制御できる可 能性がある. 沈降静水圧測定装置はすでに市販されており, 様々なスラリーでの利用が始まっている，本稿では論文投稿 との兼ね合いでスラリー評価から湿式成形・成形体評価まで を実施した具体的なデー夕を紹介することはできなかった 


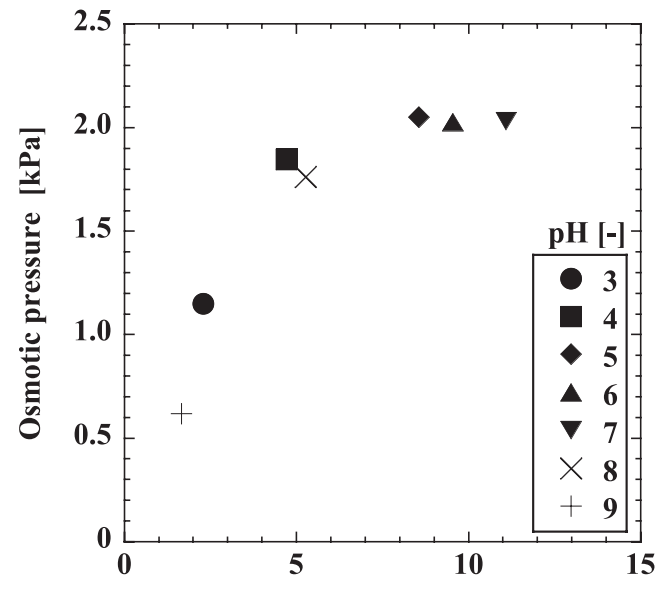

Supernatant solid concentration [mass\%]

Fig. 9 Relationship between the equilibrium osmotic pressure and the particle concentration in the sampled suspension after centrifuge for zirconia suspensions ${ }^{32)}$.

が，近日中に我々が開発した沈降静水圧測定法と，これまで 実施されてきたーザー回折・散乱法による粒子径分布測定を 利用する方法, 回転粘度計による見かけ粘度の測定を利用す る方法とを同一サンプルで比較した結果を発表する予定であ る. 沈降静水圧測定法は濃厚系スラリーの評価に特に有効 で，原理的にはあらゆるスラリーに適用可能な，極めて沉用 性の高い評価法である。 今後, さらに多くのスラリーで沈降 静水圧測定が実施され，これまでの勘と経験による制御から 脱却する一助となることを期待している.

またナノ粒子スラリーの浸透圧測定についても，実際に複 合材料を作製したときにどのような違いが出るのかを検討中 で，こちらも近いうちに結果を発表したいと考えている。ナ ノ粒子スラリーはまだまだ実用化研究段階にあり公開が難し いものが多いと思われるが，浸透圧測定による分散評価の実 例を増やしていくようにしたいと考えている.

\section{謝辞}

本研究の一部は JST 平成 29 年度研究成果最適展開支援プ ログラム（A-STEP）産業ニーズ対応タイプ「セラミックス の高機能化と製造プロセス䪊」の支援のもとで実施しまし た、ここに記して謝意を表します。また本稿には，著者が名 古屋大学大学院工学研究科に所属していた頃に取り組んだ研 究成果も含まれて抢ります. 椿淳一郎名古屋大学名誉教授, 並びに椿研究室の卒業生各位に感謝申し上げます.

\section{文献}

1) J. S. Reed: Principles of Ceramics Processing $2^{\text {nd }}$ edition, (1995) 492-542.

2) J. S. Reed: Principles of Ceramics Processing $2^{\text {nd }}$ edition, (1995) 277-304.

3) J. Tsubaki, T. Mori: PHARMSTAGE, 5 (2005) 65-77.
4) T. Mori, J. Tsubaki: J. Soc. Powder Technol., Japan, 45 (2008) 27-35.

5) T. Mori: J. Soc. Powder Technol., Japan, 46 (2009) 269-274.

6) T. Mori: Tosou Kougaku, 48 (2013) 248-254.

7) M. Rhodes: Introduction to Particle Technology $2^{\text {nd }}$ edition, (2008) 132-134

8) R. J. Hunter: Foundations of Colloid Science $2^{\text {nd }}$ edition, (2000) 141-144.

9) F. A. Morrison: Understanding Rheology, (2001) 458-459.

10) S. Takeda, P. J. Goetz: Colloids Surfaces A, 143 (1998) 35-39.

11) H. Mahdjoub, P. Roy, C. Filiatre, G. Bertrand, C. Coddet: J. Euro. Ceram. Soc., 23 (2003) 1637-1648.

12) R. R. Rao, H. N. Roopa, T. S. Kannan: Ceram. Inter., 25 (1999) 223-230

13) L. V. Woodcock: Lect. Notes Phys. 277 (1987) 113-124.

14) J. Tsubaki, M. Kato, M. Miyazawa, T. Kuma, H. Mori: Chem. Eng. Sci., 56 (2001) 3021-3026.

15) J. Tsubaki, H. Mori, M. Kato, K. Okuda, Y. Yoshida, T. Yokoyama: J. Ceram. Soc. Japan, 106 (1998) 616-620.

16) R. Greenwood, E. Roncari, C. Galassi: J. Euro. Ceram. Soc., 17 (1997) 1393-1401.

17) J. J. Guo, J. A. Lewis: J. Am. Ceram. Soc., 83 (2000) 266-272.

18) J. Davies, G. P. Binner: J. Euro. Ceram. Soc., 20 (2000) 15391553.

19) B. Singh, R. Menchvez, C. Takai, M. Fuji, M. Takahashi: J. Colloid Inter. Sci., 291 (2005) 181-186.

20) M. Takahashi, M. Oya, M. Fuji: J. Soc. Powder Technol., Japan, 40 (2003) 410-417.

21) K. S. Chou, L. J. Lee: J. Am. Ceram. Soc., 72 (1989) 1622-1627.

22) D. Hotza, P. Greil: Materials Science and Engineering A, 202 (1995) 206-217.

23) T. Mori, R. Kitagawa: Ceram. Inter., 43 (2017) 13422-13429.

24) T. Mori, K. Kuno, M. Ito, J. Tsubaki, T. Sakurai: Adv. Powder Technol., 17 (2006) 319-332.

25) T. Tanaka, K. Asai, T. Mori, J. Tsubaki: J. Soc. Powder Technol., Japan, 48 (2011) 761-767.

26) H. Ohtsuka, H. Mizutani, S. Iio, K. Asai, T. Kiguchi, H. Satone, T. Mori, J. Tsubaki: J. Euro. Ceram. Soc., 31 (2011) 517-522.

27) T. Mori, J. Tsubaki, J-P O'shea, G.V. Franks: Chem. Eng. Sci., 85 (2013) 38-45.

28) C. A. Quant, K. T. Marla, J. C. Meredith: Colloids Surf. A, 317 (2008) 129-135.

29) N. Carnahan, K. E. Starling: J. Chem. Phys., 51 (1969) 635-636.

30) M. Strauss, T. A. Ring, H. K. Bowen: J. Colloid Inter. Sci., 118 (1987) 326-334.

31) T. Mori: Bunri Gijyutsu, 46 (2016) 203-207.

32) T. Mori, T. Muramatsu, T. Mori: J. Jpn. Soc. Colour Mater., 90 (2017) 305-314. 